\title{
Do hereditary syndrome-related gynecologic cancers have any specific features?
}

\author{
Nelson Neto ${ }^{1}$ - Teresa Margarida Cunha ${ }^{2}$
}

Received: 29 May 2015 / Revised: 20 July 2015 / Accepted: 29 July 2015 / Published online: 4 September 2015

(C) The Author(s) 2015. This article is published with open access at Springerlink.com

\begin{abstract}
Hereditary syndromes are responsible for $10 \%$ of gynaecologic cancers, among which hereditary breastovarian cancer and hereditary non-polyposis colon cancer syndromes, known as HBOC and Lynch syndromes respectively, present the highest relative risk. The latter predisposes to endometrial cancer and both contribute to ovarian cancer. Cowden syndrome-related endometrial cancer and the increased risk of ovarian, uterine and cervical cancers associated with Peutz-Jeghers syndrome, are also demonstrated, while Li-Fraumeni syndrome patients are prone to develop ovarian and endometrial cancers. Despite these syndromes' susceptibility to gynaecologic cancers being consensual, it is still not clear whether these tumours have any epidemiologic, clinical, pathologic or imaging specific features that could allow any of the intervening physicians to raise suspicion of a hereditary syndrome in patients without known genetic risk. Moreover, controversy exists regarding both screening and surveillance schemes. Our literature review provides an updated perspective on the evidence-based specific features of tumours related to each of these syndromes as well as on the most accepted screening and surveillance guidelines. In addition, some illustrative cases are presented.
\end{abstract}

Nelson Neto

neto_nelson@hotmail.com

1 Radiology Department, Centro Hospitalar de Lisboa Ocidental, Estrada do Forte do Alto do Duque, 1449-005 Lisboa, Portugal

2 Radiology Department, Instituto Português de Oncologia de Lisboa Francisco Gentil, Rua Professor Lima Basto,

1009-023 Lisboa, Portugal
Teaching Points

- HBOC syndrome is mainly associated with ovarian HGSC, which arises in fallopian fimbriae.

- LS-related endometrial tumours show histological diversity and predilection for lower uterine segment.

- LS and CS-related ovarian cancers are mostly of non-serous type, usually endometrioid.

- Ovarian SCTAT and cervical adenoma malignum are strongly associated with PJS.

- Unfortunately, hereditary gynaecologic cancers do not seem to have distinctive imaging features.

Keywords Gynaecologic neoplasms · Hereditary cancer syndromes $\cdot$ Neoplasms by histological type $\cdot$ Diagnostic imaging $\cdot$ Practice guideline

\section{Introduction}

Recently, there have been significant advances in the knowledge of female genital tract malignancies related to hereditary cancer susceptibility syndromes. According to the American Society of Clinical Oncology, hereditary syndromes are responsible for about $10 \%$ of gynaecologic cancers [1].

One striking example is the discovery of the association between germline mutations in breast cancer (BRCA) 1 and 2 genes and ovarian cancers in hereditary breast-ovarian cancer (HBOC) syndrome. Another one is the role of germline mutations in DNA mismatch repair (MMR) genes in endometrial and ovarian carcinogenesis related to hereditary nonpolyposis colon cancer, also known as Lynch syndrome (LS).

Increased risk of endometrial cancer caused by mutation in the phosphatase and tensin homolog (PTEN) gene in Cowden syndrome (CS) is also demonstrated, as well as ovarian, uterine and cervical cancers related to Peutz-Jeghers syndrome 
(PJS), due to liver kinase b1 (LKB1/STK11) gene mutation. Ovarian and endometrial cancers also occur excessively in patients with Li-Fraumeni syndrome (LFS), although the understanding of the contribution of this inherited germline mutation in p53 is less established.

Despite the clear evidence of these inherited disorders' susceptibility to gynaecologic cancers, it is still not generically clear whether these tumours have any epidemiologic, clinical, pathologic or imaging specific features that could allow any of the intervening physicians to raise suspicion of a hereditary syndrome in patients without known genetic risk. Moreover, their screening and surveillance schemes remain controversial.

Our literature review provides an updated perspective on the evidence-based specific features of tumours related to each of these syndromes, as well as on the most accepted screening and surveillance guidelines. In addition, some illustrative cases are presented.

\section{Hereditary breast-ovarian cancer syndrome}

Ovarian cancer is the most lethal gynaecologic cancer, $70 \%$ being detected with advanced disease and therefore having poor prognosis, with a 5-year survival rate of only 15 to $25 \%$ for stage IV $[2,3]$.

$90 \%$ have epithelial origin [4], hereditary ones accounting for at least $10 \%$ of cases $[2,5,6]$ and the majority being due to mutations in BRCA1 gene [5, 7]. Lifetime risk for ovarian cancers is $40-66 \%$ and $10-20 \%$ in BRCA1 and BRCA2 germline mutation carriers, respectively [8-11], in contrast to $1.8 \%$ in the general population [12].

BRCA1 locus on chromosome 17q and BRCA2 on chromosome $13 \mathrm{q}$ both function as tumour suppressor genes [13-15]. These mutations, also associated with increased risk of breast cancer, are both on the basis of HBOC and sitespecific ovarian cancer syndromes. Ethnic background significantly influences the mutation rates, which are particularly high among Ashkenazi Jews compared to other populations $[16,17]$.

Mean age of presentation of ovarian cancer in HBOC syndrome is $51-53$ years, about 10 years earlier than in nonBRCA mutations carriers [5, 12].

Concerning its pathology, the great majority are high-grade serous carcinomas (HGSC) of papillary type, diagnosed at advanced stage $[2,7,12,18]$. Despite this, survival of ovarian cancer seems to be surprisingly better in these women than in sporadic ones [7], for unknown reasons.

Both cases of BRCA1 mutation-related ovarian cancer presented (Figs. 1 and 2) were high-grade tumours with no tubal involvement, diagnosed at younger ages than is typical for the general population, which metastasized to lymph nodes. On the other hand, a localized ovarian tumour in a BRCA2 mutation carrier is presented in Fig. 3.

A curious detail regarding the origin of most ovarian HGSC in patients with HBOC, suggested by recent studies of prophylactically removed ovaries, is that instead of arising primarily from the ovary as originally assumed, these tumours actually seem to arise from the fallopian tube fimbriae and are characterized by p53 signature mutations, typical of tubal
Fig. 1 a-d. High-grade serous carcinoma of the right ovary in a 56-year-old BRCA1-mutation carrier woman. Magnetic resonance imaging (MRI) scan with T2-weighted (a), postgadolinium fat-suppressed (FS) T1-weighted (b) and diffusionweighted (c) images, showing a complex cystic-solid multilobulated right adnexal mass with restricted diffusion on b600 image (c), with pathologically proved capsule rupture, but without metastases. Contrastenhanced computed tomography (CECT) obtained 1 year later due to a left supraclavicular palpable painful mass confirms the presence of a lymph node metastasis (arrow in d)
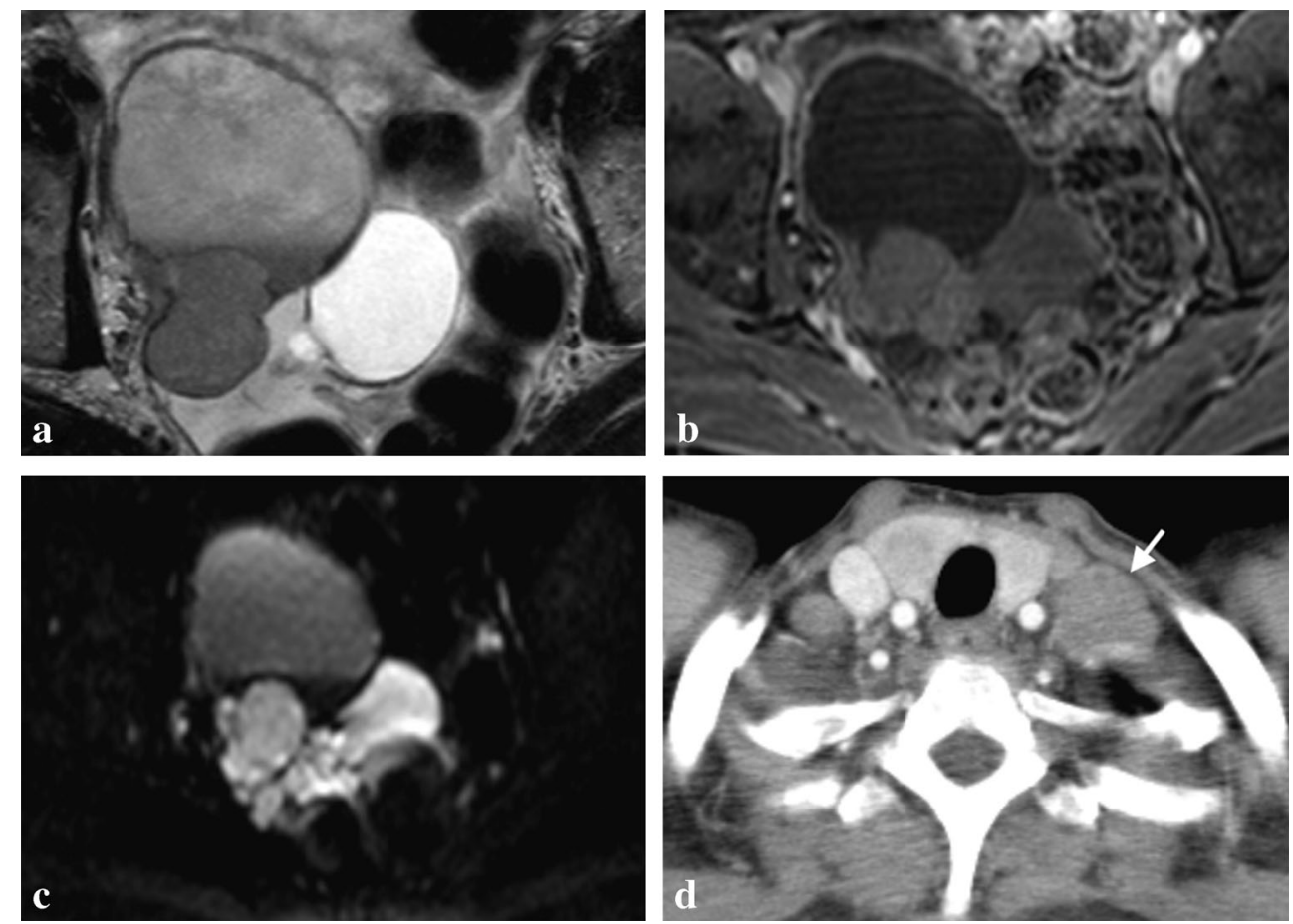
Fig. 2 a-d. Bilateral undifferentiated ovarian carcinomas in a 34-year-old BRCA1-mutation carrier woman. CT scan shows a large multiloculated cystic left adnexal mass with thick septa (a). A right adnexal mass, similar to that one described in image a, but with a more prominent solid component, was also present (b). Left paraaortic lymph node metastases are also present $(\mathbf{c})$. Moderate ascites is evident in all images but there was no pleural effusion (d). Pathologic examination ruled out ovarian capsule and tubal invasion
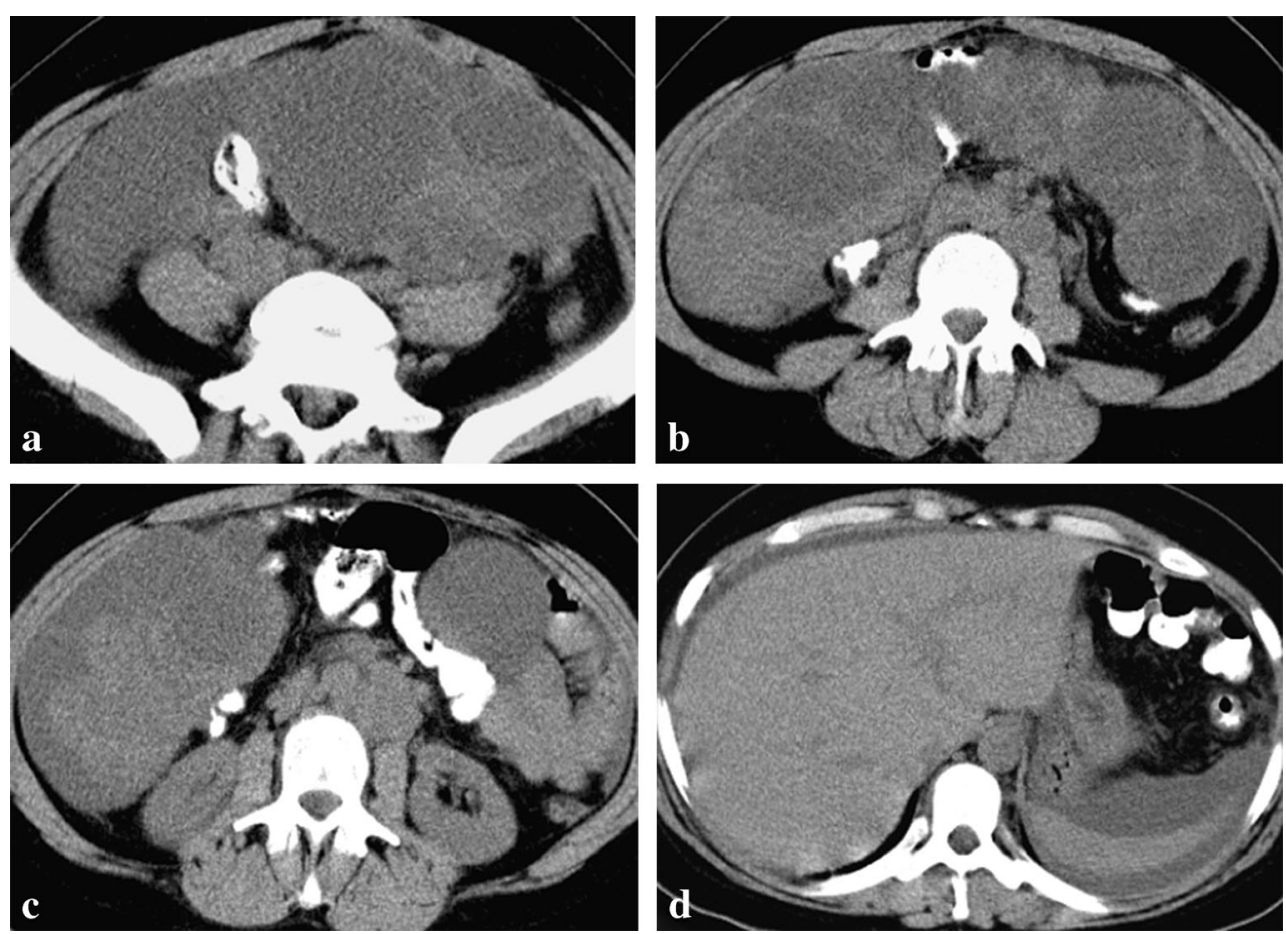

intraepithelial carcinomas. In addition, these studies failed to identify reproducible precursor lesions in the ovaries [2, 12]. For these reasons, some experts consider ovarian and fallopian tube cancer in BRCA-mutations carriers to be more properly termed as adnexal carcinomas [19]. However, interpretation of p53 signatures, defined as p53 positivity by immunohistochemical staining in at least 12 secretory cells with a low proliferative index, must be done cautiously, as it does not mean a neoplastic lesion is present and is a quite common occurrence in fallopian tubes, regardless of BRCA status [12].

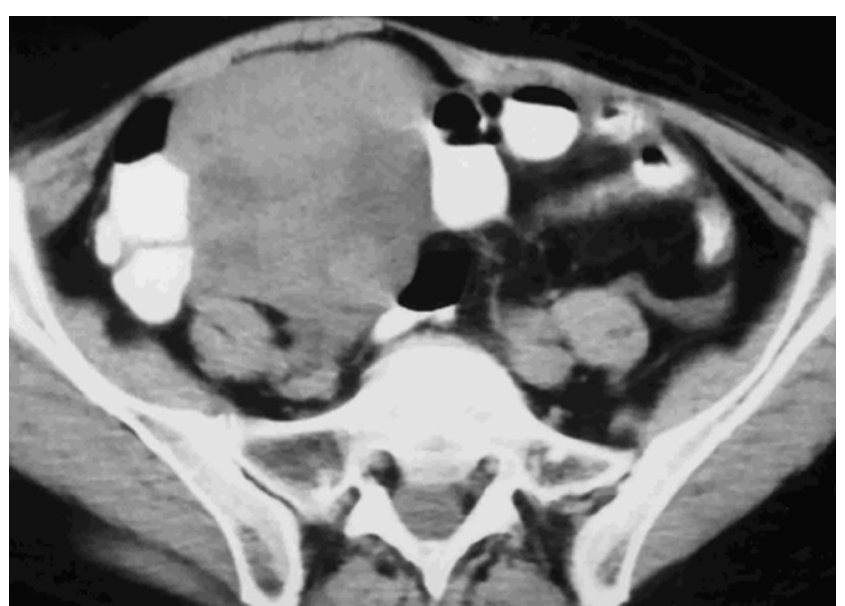

Fig. 3 Undifferentiated ovarian carcinoma in a 59-year-old BRCA2mutation carrier woman. CT scan demonstrates a large multilobulated complex cystic-solid right adnexal mass. There were neither ascites nor enlarged lymph nodes
Another cancer type, in whose progression the loss of BRCA1 function with concurrent deletion of p53 may be an important step, is uterine leiomyosarcoma, a rare gynaecologic malignancies with a low survival rate [20].

As genetic testing for BRCA genes is not cost-effective for the general population, thus far the selection of candidates still relies on family history [1]. Once a genetic risk is confirmed, management is not consensual, but usually includes serial serum determinations of multiple tumour markers together with transvaginal ultrasound, another option being prophylactic oophorectomy after planned childbearing is completed. Although a protective effect of oral contraceptives against ovarian cancer is nearly proven, their routine prophylactic use is no longer recommended due to the possible increased relative risk of breast cancer in patients with $\mathrm{HBOC}$ syndrome $[5]$.

\section{Lynch syndrome}

Lynch syndrome (LS), caused by an autosomal-dominant hereditary germline mutation in one of the MMR genesMSH2, MLH1 and MSH6, in decreasing order [21] — predisposes to early onset of multiple cancer types, including colon, endometrial and ovarian ones, sometimes with synchronous presentation [22, 23]. MMR maintain genomic stability by correcting mismatches generated during DNA replication, their malfunction promoting cancer due to microsatellite instability [24]. However, microsatellite instability is also 
present in $15-20 \%$ of corresponding sporadic cancers, usually due to MLH1 methylation [25].

Traditionally associated with colorectal cancer, it is nowadays consensual that women with LS are at equal or even higher risk for development of gynaecologic malignancy [26-29], as their sentinel cancer in more than half of cases $[30,31]$. Their lifetime cumulative risk of endometrial cancer is $40-60 \%[26,28,29,31]$ and that of ovarian cancer is 10 $12 \%[18,21,27,32-34]$, appearing to be particularly high for MSH2-mutation carriers [35-37] and accounting for $2 \%$ of all ovarian cancers [34].

Although it has long been thought that the average age of onset of LS-related endometrial cancer is $45-50$ years, in contrast to 65 years in sporadic cases $[5,38,39]$, other studies have suggested that a cutoff age of 50 years old for screening could lead to $25-60 \%$ of LS missing cases [40, 41], therefore a cutoff age of 60 has already been advocated [22]. Regardless of this controversy, a diagnosis of endometrial cancer at a young age should raise suspicion for LS, especially if the most typical constitutional factor of sporadic endometrial cancerobesity - is absent and family history is positive [42, 43]. Mean age for developing ovarian cancer is $40-48$ years among patients with LS [5, 36, 39].

While sporadic endometrial cancers that have microsatellite instability are almost exclusively of endometrioid type, usually well to moderately differentiated, those related to LS tend to be histologically more diverse also occurring nonendometrioid carcinomas, including serous, clear cell and undifferentiated ones, although the majority is still of endometrioid type [38, 43]. LS-related endometrial cancers also show a predilection for the lower uterine segment, with up to one-third of these tumours arising in this location [44-46].

Although certain distinctive microscopic features of endometrioid carcinomas, like poor differentiation, tumour heterogeneity and increased tumour-infiltrating lymphocytes, have been shown to be suggestive of the presence of high levels of microsatellite instability [40, 47, 48], there are conflicting data regarding their utility [46].

Contrary to ovarian cancers of the general population or that are HBOC syndrome-related, those related to LS are mostly of the non-serous type, including endometrioid, clear cell and undifferentiated carcinomas [36, 49]. Endometrioid is most commonly associated with LS [36] and the second most frequent histological subtype in the general population [50], the majority being well to moderately differentiated and pursuing favourable clinical outcomes [36, 51]. There may be synchronous endometrial thickening, representing either hyperplasia or carcinoma [52]. Among ovarian carcinomas associated with MMR defects, including LS-related ones, clear cell subtype represents the majority [35].

Prognostic impact of MMR status is not clear for either endometrial or ovarian carcinomas [12].

LS cases illustrated in Figs. 4 and 5 correspond to patients whose sentinel cancers were gynaecologic, the latter with synchronous endometrial and ovarian tumours.

Current gynaecologic cancer screening guidelines for women with LS, which include annual endometrial
Fig. 4 a-d. Mixed serousendometrioid carcinoma of the uterus in a 66-year-old woman with Lynch syndrome.

Ultrasound (a) shows a solid polypoid mass inside the uterine cavity and a small hydrometra. MRI scan demonstrates a solid well-circumscribed endometrial tumour, hypoenhancing compared with myometrium on post-gadolinium FS T1-weighted image (b). Diffusion restriction on the b1000 image (c) with a low apparent diffusion coefficient (ADC) value (d) is also evident, consistent with its malignant nature. The tumour was confined to the corpus uteri with no myometrial invasion
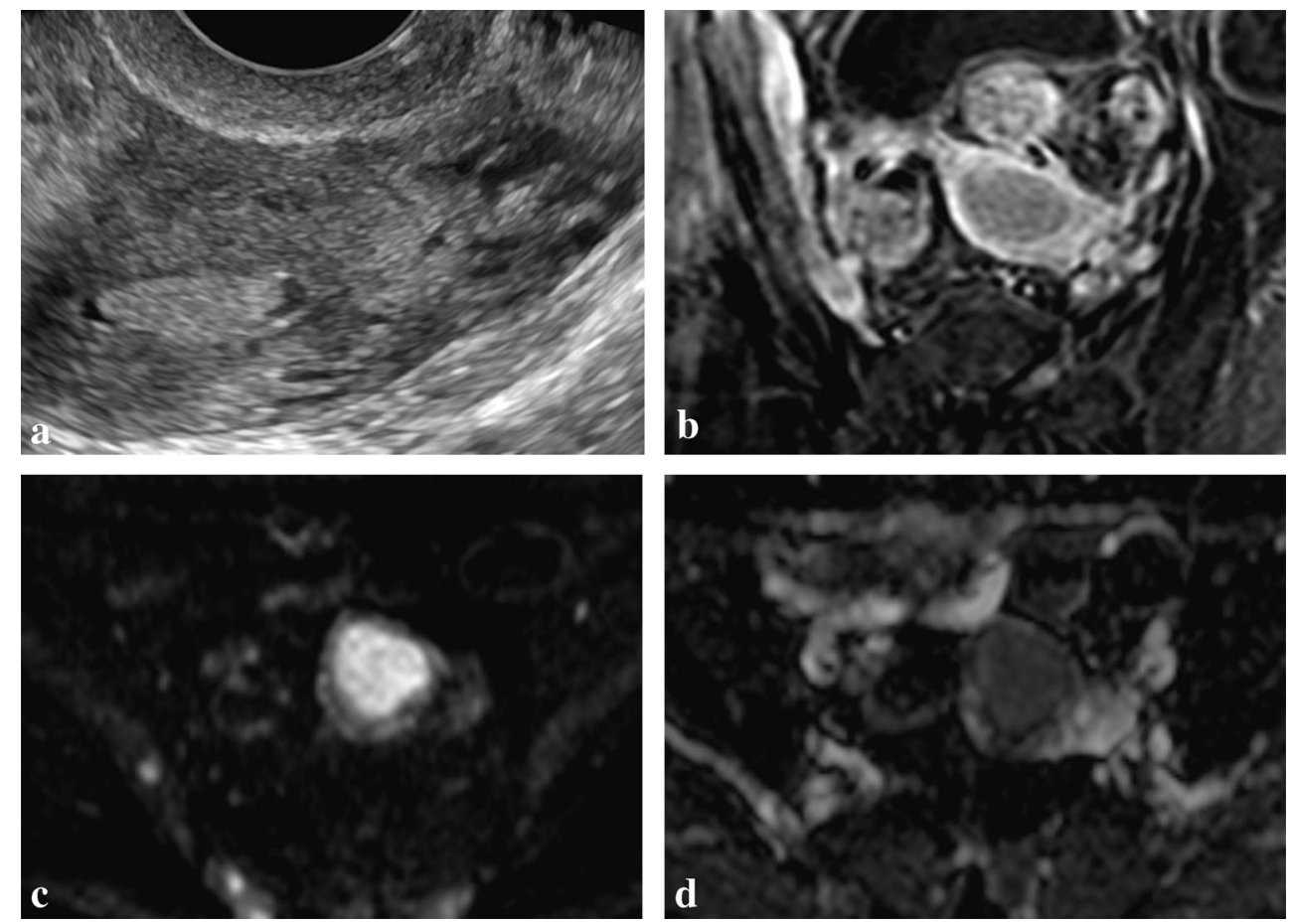

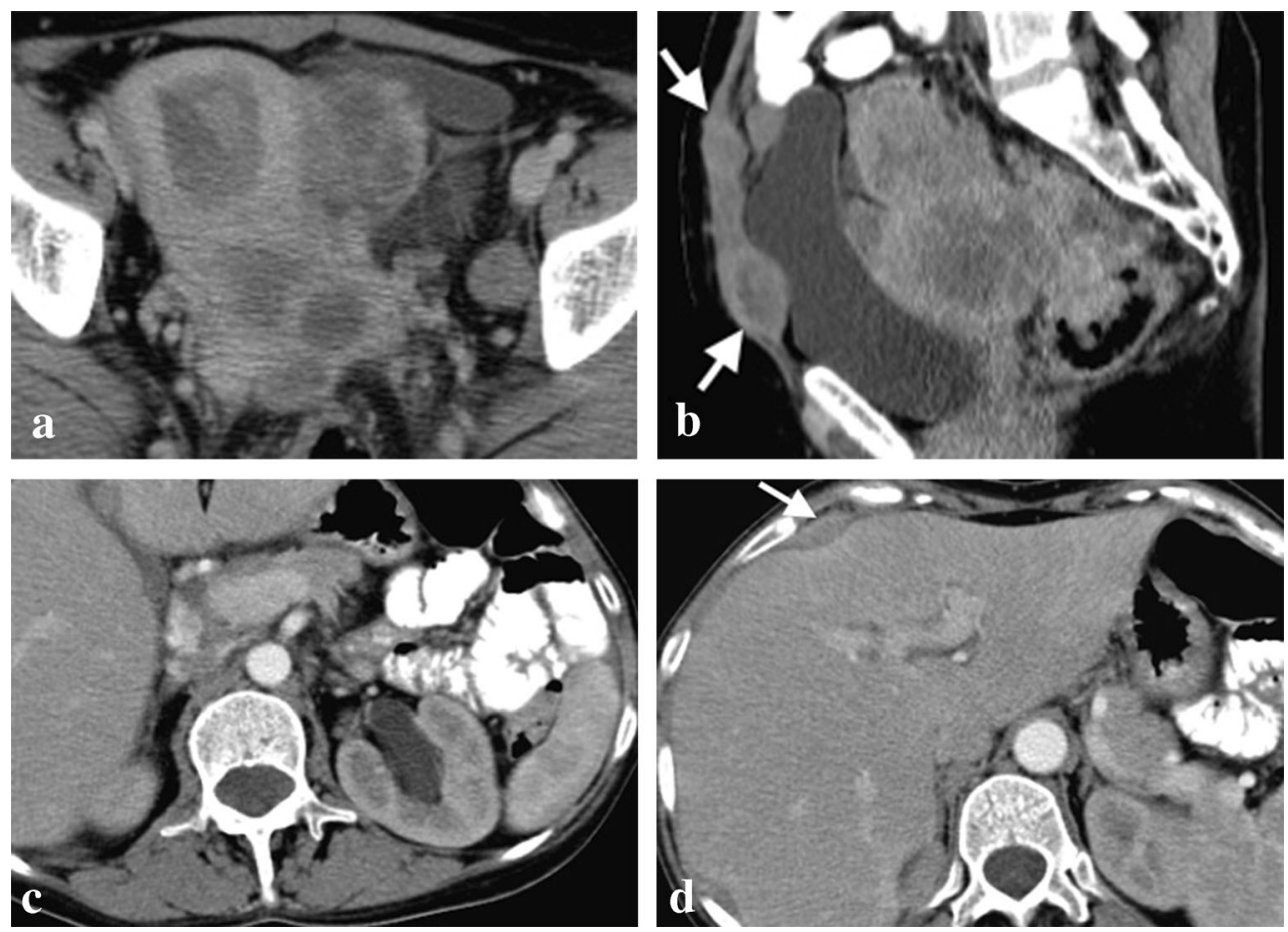

Fig. 5 a-d. Poorly differentiated endometrioid carcinomas of the left ovary and of the endometrium in a 56-year-old woman with Lynch syndrome. CECT shows a large complex cystic-solid multiloculated left adnexal mass with no cleavage plane from the uterine corpus (a) in concordance with invasion of the myometrium, as pathologically demonstrated. The same image depicts the endometrial tumour, seen as a polypoid solid lesion within the uterine cavity surrounded by fluid,

sampling and transvaginal ultrasound beginning at 30 35 years, are not considered to be effective, but are still a reasonable option $[12,53]$.

\section{Cowden syndrome}

Cowden syndrome (CS), part of a broader category termed PTEN hamartoma tumour syndrome, is characterized by a mutation in the PTEN tumour-suppressor gene, which leads to uncontrolled cell division and the formation of hamartomatous neoplasms and certain cancers, representing an increased lifetime risk of endometrial carcinomas of $13-19 \%$ [54].

Histologically, reported cases of CS-related endometrial carcinomas [54-57] and the one illustrated in Fig. 6 are of endometrioid type.

Although still not validated, the adoption of the screening guidelines for LS, including annual endometrial biopsies beginning at age 30 to 35 , or 5 years before the earliest family diagnosis of endometrial cancer and annual ultrasound examination with biopsy of suspicious areas for postmenopausal women, has already been proposed [54]. Formal evaluation proved to be confined to the inner half of the endometrium. A CECT scan obtained 2 months after hysterectomy with bilateral adnexectomy without pelvic lymphadenectomy demonstrates in the sagittal plane (b) a large pelvic mass arising from the vaginal cuff consistent with tumour recurrence, as well as two abdominal wall implants (arrows). Left hydronephrosis secondary to pelvic wall invasion (c) and a hepatic subcapsular implant (d) are also evident in the same study

for CS when endometrial cancer is diagnosed in adolescence has also been suggested [55].

\section{Li-fraumeni syndrome}

Li-fraumeni syndrome (LFS) is an extremely rare autosomaldominant hereditary disorder characterized by a germline mutation in the tumour-suppression gene $\mathrm{p} 53$, which leads to an estimated 50-fold risk over the general population of developing several types of cancer [58], more than half occurring before age 30 [59]. Although endometrial and ovarian cancers have been found to occur excessively in at least some families who have met criteria for LFS, their link to the syndrome is not definitely established, occurring at a much lower rate than other cancer types, like breast cancer [60].

Actually, the fact that distal fallopian tubes of women with LFS are exquisitely prone to developing p53 signatures, identical to those described in BRCA1/2-mutations carriers and general population, does not mean an association with ovarian cancer, as at least one more genotoxic event is needed to produce the malignant phenotype [61].

There are no studies specifically examining the relation between LFS and endometrial cancer. 


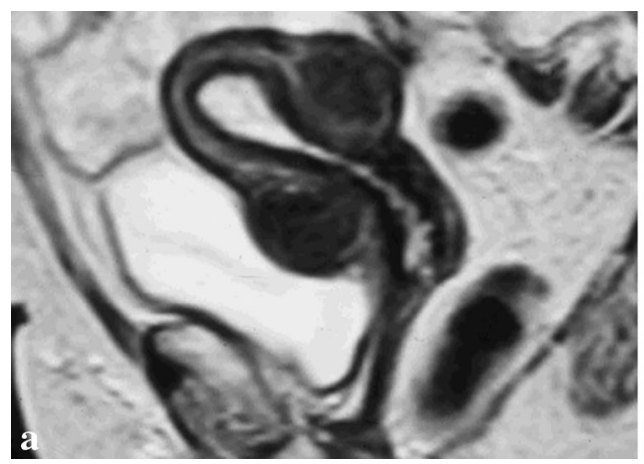

Fig. 6 a, b. High-grade endometrioid carcinoma within an endometrial hyperplastic polyp in a 62-year-old woman with Cowden syndrome. T2weighted image (a) shows distension of the uterine cavity due to a polyp, more evident on post-gadolinium FS T1-weighted image (b), which is

\section{Peutz-jeghers syndrome}

Peutz-jeghers syndrome (PJS) is a rare autosomal dominant disease due to mutations in the tumour-suppressor gene STK11 [62], which predisposes not only to hamartomatous gastrointestinal polyps and mucocutaneous pigmentation, but also to numerous malignancies, including gynaecologic ones, the latter having a reported relative risk of $27.7 \%$ in comparison to the general population [63].

Risk of ovarian, cervical and uterine cancers associated with PJS is $18-21 \%, 10 \%$ and $9 \%$, respectively [64].

PJS-related gynaecological cancers are of some characteristic histological types, particularly the sex cord tumours with annular tubules (SCTAT) of the ovary [63, 65-67], $36 \%$ occurring in association with this syndrome [65], although with lower risk of malignant transformation than in the general population [63]. This distinctive ovarian neoplasm, whose predominant component has morphologic features intermediate between those of granulosa cell and Sertoli cell tumours, may produce both oestrogen and progesterone [68]. This histological type is followed by Sertoli cell, mucinous, serous and mature teratoma [67].

There is also evidence that patients with PJS are prone to develop endometrial adenocarcinomas [69, 70], especially highly invasive ones [70].

Among cervical tumours, there is an important association with minimal deviation adenocarcinoma [65, 66, 71], known as adenoma malignum, with $10 \%$ of all cases occurring in PJS patients [66]. This is a well-differentiated mucinous adenocarcinoma with highly aggressive behaviour, despite its deceptively benign appearance and very scarce cytological features of malignancy within the tumour [71].

Gynaecologic cancer screening surveillance recommendations for patients with PJS include annual Papanicolaou test by age 18 and annual pelvic examination and ultrasound by age

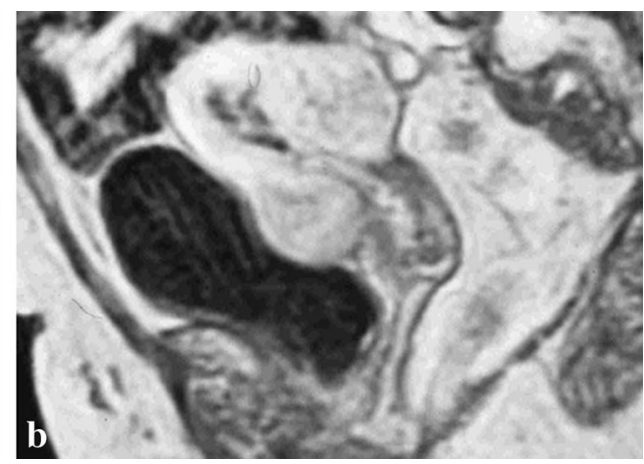

hypoenhancing compared with myometrium. Normal uterine zonal anatomy is preserved. Note the bosselated and smooth outer contour of the uterus due to leiomyomas

20 [72], which should also target the potential malignant change of ovarian SCTAT [63].

\section{Conclusions}

Regardless of some genetic specifications, the following particularities concerning each of the syndromes discussed above are consensual nowadays:

- HBOC syndrome is mainly associated with ovarian HGSC, which seem to arise in the fallopian fimbriae and have better prognosis than sporadic cancers.

- LS predisposes to endometrial cancer, at a lower rate than ovarian cancers. Endometrial cancers show a predilection for the lower uterine segment and tend to be histologically more diverse in contrast to their sporadic counterparts, including non-endometrioid carcinomas. Both LS and CS-related ovarian cancers are mostly of non-serous type, usually endometrioid.

- LFS only slightly increases the risk of endometrial and ovarian cancers.

- PJS increases the risk of ovarian, cervical and uterine cancers, in decreasing order, ovarian SCTAT and cervical adenoma malignum being strongly associated.

- Unfortunately, hereditary gynaecologic cancers do not seem to have any imaging characteristics that might be reliably used to distinguish them from sporadic cancers.

- In order to ensure early identification of high-risk patients, every time a gynaecologic malignancy is diagnosed under the expected age in the general population, a careful anamnesis including familial history of cancer and genetic confirmation when indicated is required.

- Screening and surveillance schemes usually consist of an annual pelvic examination with endometrial sampling and ultrasound beginning in young adulthood. 
Open Access This article is distributed under the terms of the Creative Commons Attribution 4.0 International License (http:// creativecommons.org/licenses/by/4.0/), which permits unrestricted use, distribution, and reproduction in any medium, provided you give appropriate credit to the original author(s) and the source, provide a link to the Creative Commons license, and indicate if changes were made.

\section{References}

1. ASCO/Society of Gynecologic Oncology Special Session (2004) Clinical management of patients with hereditary predisposition to gynecologic (ovarian and endometrial) cancers. Program and abstracts of the 40th Annual Meeting of the American Society of Clinical Oncology. New Orleans, Louisiana

2. Lalwani N, Prasad SR, Vikram R et al (2011) Histologic, molecular, and cytogenetic features of ovarian cancers: implications for diagnosis and treatment. Radiographics 31(3):625-646

3. Landis SH, Murray T, Bolden S et al (1998) Cancer statistics. CA Cancer J Clin 48:6-29

4. Feeley KM, Wells M (2001) Precursor lesions of ovarian epithelial malignancy. Histopathology 38(2):87-95

5. Lynch HT, Casey MJ, Shaw TG et al (1998) Hereditary Factors in Gynecologic Cancer. Oncologist 3(5):319-338

6. Lynch HT, Lynch JF, Conway TA (1993) Hereditary ovarian cancer. In: Rubin SC, Sutton GP (eds) Ovarian cancer. McGraw-Hill, New York, pp 189-217

7. Rubin SC, Benjamin I, Behbakht K et al (1996) Clinical and pathological features of ovarian cancer in women with germ-line mutations of BRCA1. N Engl J Med 335(19):1413-1416

8. Easton DF, Bishop DT, Ford D et al (1993) Genetic linkage analysis in familial breast and ovarian cancer: results from 214 families. Am J Hum Genet 52:678-701

9. Easton DF, Ford D, Bishop DT et al (1995) Breast and ovarian cancer incidence in BRCA1 mutation carriers. Am J Hum Genet 56:265-271

10. Domanska K, Malander S, Masback A et al (2007) Ovarian cancer at young age: the contribution of mismatch-repair defects in a population-based series of epithelial ovarian cancer before age 40 . Int J Gynecol Cancer 17:789-793

11. Schmeler KM, Lynch HT, Chen LM et al (2006) Prophylactic surgery to reduce the risk of gynecologic cancers in the Lynch syndrome. N Engl J Med 354:261-269

12. Longacre T, Folkins A (2011) 217 Gynecologic familial cancer syndromes: what does the practicing pathologist need to know? American society for clinical pathology. Annual Meeting. Las Vegas, Nevada

13. Liu FS, Ho ESC, Shih A (1997) Mutational analysis of the BRCA1 tumor suppressor gene in endometrial carcinoma. Gynecol Oncol 66:449-453

14. Haber D, Harlow E (1997) Tumor-suppressor genes: evolving definitions in the genomic age. Nat Genet 16:320-322

15. Merajver SD, Frank TS, Xu J et al (1995) Germline BRCA1 mutations and loss of the wild-type allele in tumors from families with early onset breast and ovarian cancer. Clin Cancer Res 1:539-544

16. Struewing JP, Hartge P, Wacholder $S$ et al (1997) The risk of cancer associated with specific mutations of BRCA1 and BRCA2 among Ashkenazi Jews. N Engl J Med 336:1401-1408

17. Abeliovich D, Kaduri L, Lerer I et al (1997) The founder mutations 185delAG and 5382insC in BRCA1 and 6174delT in BRCA2 appear in $60 \%$ of ovarian cancer and $30 \%$ of early-onset breast cancer patients among Ashkenazi women. Am J Hum Genet 60:505-514

18. Bewtra C, Watson P, Conway T et al (1992) Hereditary ovarian cancer: a clinicopathological study. Int J Gynecol Pathol 11:180-187
19. Piek JM, Dorsman JC, Zweemer RP et al (2003) Women harboring BRCA1/2 germline mutations are at risk for breast and female adnexal carcinoma. Int J Gynecol Pathol 22(3):315-316

20. Xing D, Scangas G, Nitta M et al (2009) A role for BRCA1 in uterine leiomyosarcoma. Cancer Res 69(21):8231-8235

21. Bonadona V, Bonaïti B, Olschwang S et al (2011) Cancer risks associated with germline mutations in MLH1, MSH2, and MSH6 genes in Lynch syndrome. JAMA 305:2304-2310

22. Wang Y, Li J, Cragun J et al (2013) Lynch syndrome related endometrial cancer: clinical significance beyond the endometrium. $\mathrm{J}$ Hematol Oncol 6:22

23. Soliman PT, Broaddus RR, Schmeler KM et al (2005) Women With Synchronous Primary Cancers of the Endometrium and Ovary: Do They Have Lynch Syndrome? J Clin Oncol 23(36):9344-9350

24. Jass JR, Cottier DS, Jeevaratnam P et al (1995) Diagnostic use of microsatellite instability in hereditary non-polyposis colorectal cancer. Lancet 346:1200-1201

25. Peltomaki P (2003) Role of DNA mismatch repair defects in the pathogenesis of human cancer. J Clin Oncol 21:1174-1179

26. Aarnio M, Sankila R, Pukkala E et al (1999) Cancer risk in mutation carriers of DNA-mismatch-repair genes. Int J Cancer 81(2):214-218

27. Dunlop MG, Farrington SM, Carothers AD et al (1997) Cancer risk associated with germline DNA mismatch repair gene mutations. Hum Mol Genet 6(1):105-110

28. Quehenberger F, Vasen HF, van Houwelingen HC (2005) Risk of colorectal and endometrial cancer for carriers of mutations of the hMLH1 and hMSH2 gene: correction for ascertainment. J Med Genet 42:491-496

29. Vasen HF, Stormorken A, Menko FH et al (2001) MSH2 mutation carriers are at higher risk of cancer than MLH1 mutation carriers: a study of hereditary nonpolyposis colorectal cancer families. J Clin Oncol 19:4074-4080

30. Lu KH, Dinh M, Kohlmann W et al (2005) Gynecologic cancer as a "sentinel cancer" for women with hereditary nonpolyposis colorectal cancer syndrome. Obstet Gynecol 105:569-574

31. Vasen HF, Offerhaus GJ, den Hartog Jager FC et al (1990) The tumor spectrum in hereditary non-polyposis colorectal cancer: a study of 24 kindreds in the Netherlands. Int J Cancer 46:31-34

32. Prat J, Ribé A, Gallardo A (2005) Hereditary ovarian cancer. Hum Pathol 36(8):861-870

33. Grindedal EM, Renkonen-Sinisalo L, Vasen H et al (2010) Survival in women with MMR mutations and ovarian cancer: a multicentre study in Lynch syndrome kindreds. J Med Genet 47:99-102

34. Malander S, Rambech E, Kristoffersson U et al (2006) The contribution of the hereditary nonpolyposis colorectal cancer syndrome to the development of ovarian cancer. Gynecol Oncol 101:238-243

35. Jensen KC, Mariappan MR, Putcha GV et al (2008) Microsatellite instability and mismatch repair protein defects in ovarian epithelial neoplasms in patients 50 years of age and younger. Am J Surg Pathol 32:1029-1037

36. Ketabi Z, Bartuma K, Bernstein I et al (2011) Ovarian cancer linked to Lynch syndrome typically presents as early-onset, non-serous epithelial tumors. Gynecol Oncol 121:462-465

37. Vasen HF, Wijnen JT, Menko FH et al (1996) Cancer risk in families with hereditary nonpolyposis colorectal cancer diagnosed by mutation analysis. Gastroenterology 110:1020-1027

38. Broaddus RR, Lynch HT, Chen LM et al (2006) Pathologic features of endometrial carcinoma associated with HNPCC: a comparison with sporadic endometrial carcinoma. Cancer 106(1):87-94

39. Aarnio M, Mecklin JP, Aaltonen LA et al (1995) Life-time risk of different cancers in hereditary non-polyposis colorectal cancer (HNPCC) syndrome. Int J Cancer 64:430-433

40. Hampel H, Panescu J, Lockman J et al (2007) Comment on: Screening for Lynch Syndrome (Hereditary Nonpolyposis 
Colorectal Cancer) among Endometrial Cancer Patients. Cancer Res 67:9603

41. Ryan P, Mulligan AM, Aronson M et al (2012) Comparison of clinical schemas and morphologic features in predicting Lynch syndrome in mutation-positive patients with endometrial cancer encountered in the context of familial gastrointestinal cancer registries. Cancer 118:681-688

42. Chen S, Wang W, Lee S et al (2006) Prediction of germline mutations and cancer risk in the Lynch syndrome. JAMA 296:14791487

43. Carcangiu ML, Radice P, Casalini P et al (2010) Lynch syndromerelated endometrial carcinomas show a high frequency of nonendometrioid types and of high FIGO grade endometrioid types. Int J Surg Pathol 18:21-26

44. Westin SN, Lacour RA, Urbauer DL et al (2008) Carcinoma of the lower uterine segment: a newly described association with Lynch syndrome. J Clin Oncol 26:5965-5971

45. Goodfellow PJ, Buttin BM, Herzog TJ et al (2003) Prevalence of defective DNA mismatch repair and MSH6 mutation in an unselected series of endometrial cancers. Proc Natl Acad Sci U S A 100(10):5908-5913

46. Honore LH, Hanson J, Andrew SE (2006) Microsatellite instability in endometrioid endometrial carcinoma: correlation with clinically relevant pathologic variables. Int J Gynecol Cancer 16:1386-1392

47. Garg K, Leitao MM Jr, Kauff ND et al (2009) Selection of endometrial carcinomas for DNA mismatch repair protein immunohistochemistry using patient age and tumor morphology enhances detection of mismatch repair abnormalities. Am J Surg Pathol 33: 925-933

48. Shia J, Black D, Hummer AJ et al (2008) Routinely assessed morphological features correlate with microsatellite instability status in endometrial cancer. Hum Pathol 39:116-125

49. Lu FI, Gilks CB, Mulligan AM et al (2012) Prevalence of loss of expression of DNA mismatch repair proteins in primary epithelial ovarian tumors. Int J Gynecol Pathol 31(6):524-531

50. Gilks CB, Prat J (2009) Ovarian carcinoma pathology and genetics: recent advances. Hum Pathol 40(9):1213-1223

51. Watson P, Butzow R, Lynch HT et al (2001) The clinical features of ovarian cancer in hereditary nonpolyposis colorectal cancer. Gynecol Oncol 82:223-228

52. Jung SE, Lee JM, Rha SE et al (2002) CT and MR imaging of ovarian tumors with emphasis on differential diagnosis. RadioGraphics 22(6):1305-1325

53. Lindor NM, Petersen GM, Hadley DW et al (2006) Recommendations for the care of individuals with an inherited predisposition to Lynch syndrome: a systematic review. JAMA 296(12):1507-1517

54. ElNaggar AC, Spunt SL, Smith W et al (2013) Endometrial cancer in a 15-year-old girl: A complication of Cowden Syndrome. Gynecol Oncol Case Rep 3:18-19

55. Baker WD, Soisson AP, Dodson MK (2013) Endometrial cancer in a 14-year-old girl with Cowden syndrome: a case report. J Obstet Gynaecol Res 39(4):876-878

56. Edwards JM, Alsop S, Modesitt SC (2012) Coexisting atypical polypoid adenomyoma and endometrioid endometrial carcinoma in a young woman with Cowden Syndrome: Case report and implications for screening and prevention. Gynecol Oncol Case Rep 2(2):29-31

57. Schmeler KM, Daniels MS, Brandt AC et al (2009) Endometrial cancer in an adolescent: a possible manifestation of Cowden syndrome. Obstet Gynecol 114(2 Pt 2):477-479

58. Rédei G (2008) Encyclopedia of Genetics, Genomics, Proteomics and Informatics, vol 1, 3rd edn. Springer, p 1102

59. Le Bihan C, Moutou C, Brugieres L et al (1995) ARCAD: a method for estimating age-dependent disease risk associated with mutation carrier status from family data. Genet Epidemiol 12(1):13-25

60. Schneider K, Zelley K, Nichols KE et al (1999, Updated 2013) LiFraumeni Syndrome. In: Pagon RA, Adam MP, Ardinger HH et al (eds) GeneReviews ${ }^{\circledR}$, University of Washington, Seattle. Available via http://www.ncbi.nlm.nih.gov/books/NBK1311/

61. Xian W, Miron A, Roh M et al (2010) The Li Fraumeni Syndrome (LFS): a model for the initiation of p53 signatures in the distal fallopian tube. J Pathol 220(1):17-23

62. Jenne DE, Reimann H, Nezu J et al (1998) Peutz-Jeghers syndrome is caused by mutations in a novel serine threonine kinase. Nat Genet $18: 38-43$

63. Resta N, Pierannunzio D, Lenato GM et al (2013) Cancer risk associated with STK11/LKB1 germline mutations in PeutzJeghers syndrome patients: Results of an Italian multicenter study. Dig Liver Dis 45(7):606-611

64. Gammon A, Jasperson K, Kohlmann W et al (2009) Hamartomatous polyposis syndromes. Best Pract Res Clin Gastroenterol 23(2):219-231

65. Young R, Welch W, Dickersin GR et al (1982) Ovarian sex cord tumor with annular tubules: review of 74 cases including 27 with Peutz-Jeghers syndrome and four with adenoma malignum of the cervix. Cancer 50(7):1384-1402

66. Srivatsa PJ, Keeney GL, Podratz KC (1994) Disseminated cervical adenoma malignum and bilateral ovarian sex cord tumors with annular tubules associated with Peutz-Jeghers syndrome. Gynecol Oncol 53:256

67. Papageorgiou T, Stratakis CA (2002) Ovarian tumors associated with multiple endocrine neoplasias and related syndromes (Carney complex, Peutz-Jeghers Syndrome, von Hippel Lindau disease, Cowden's disease). Int J Gynecol Cancer 12:337-347

68. Taheri D, Afshar-Moghadam N, Mahzoni P et al (2013) Cancer problem in Peutz-Jeghers syndrome. Adv Biomed Res 2:35

69. Tanwar PS, Kaneko-Tarui T, Zhang L et al (2012) Stromal liver kinase B1 [STK11] signaling loss induces oviductal adenomas and endometrial cancer by activating mammalian Target of Rapamycin Complex 1. PLoS Genet 8(8):e1002906

70. Contreras CM, Gurumurthy S, Haynie JM et al (2008) Loss of Lkb1 provokes highly invasive endometrial adenocarcinomas. Cancer Res 68(3):759-766

71. Connolly D, Katabuchi H, Cliby W et al (2000) Somatic mutations in the STK11/LKB1 gene are uncommon in rare gynecological tumor types associated with Peutz-Jeghers syndrome. Am J Pathol 1565(1):339-345

72. Beggs AD, Latchford AR, Vasen HF et al (2010) Peutz-Jeghers syndrome: a systematic a review and recommendations for management. Gut 59:975-986 